\title{
Precocious hippocampal structural and functional changes in gestational protein- restricted male elderly offspring: an Alzheimer-simile disease model?
}

\author{
Gabriel Boer Grigoletti-Lima, Marcelo Gustavo Lopes, Ana Tereza Barufi Franco, Aparecida \\ Marcela Damico, Patrícia Aline Boer, José Antonio Rocha Gontijo [1]
}

Fetal Programming and Hydroelectrolyte Metabolism Laboratory, Medicine and Experimental Surgery Center, Internal Medicine Department, Faculty of Medical Sciences at State University of Campinas, Campinas, SP, Brazil

[1] Corresponding author:

José Antonio Rocha Gontijo, MD, Ph.D,

Internal Medicine Department, School of Medicine, State University of Campinas, Campinas, SP, Brazil

Phone: +55 19 35217346, Fax: +55 193521-8925

E-mail: gontijo@fcm.unicamp.br

Patrícia Aline Boer, BSC, Ph.D.,

Department of Internal Medicine, School of Medicine, State University of Campinas, Campinas, SP, Brazil

Phone: +55 19 35217346, Fax: +55 193521-8925

E-mail: alineboer@yahoo.com.br

Gabriel Boer Grigoletti-Lima, Ph.D

Department of Internal Medicine, School of Medicine, State University of Campinas, Campinas, SP, Brazil

Phone: +55 19 35217346, Fax: +55 193521-8925

E-mail: gabrielboergrigoletti@gmail.com

Marcelo Gustavo Lopes, MD,

Department of Internal Medicine, School of Medicine, State University of Campinas, Campinas, SP, Brazil

Phone: +55 19 35217346, Fax: +55 19 3521-8925 
E-mail: marcelolopes46@gmail.com

Ana-Tereza Barufi Franco, MS, Ph.D,

Department of Internal Medicine, School of Medicine, State University of Campinas, Campinas, SP, Brazil

Phone: +55 19 35217346, Fax: +55 19 3521-8925

E-mail: anatbfranco@yahoo.com.br

Aparecida Marcela Damico, MS,

Department of Internal Medicine, School of Medicine, State University of Campinas, Campinas, SP, Brazil

Phone: +55 1935217346 , Fax: +55 $193521-8925$

E-mail: marceladamico@hotmail.com

Authors' contributions: GBGL: Data curation, Investigation, Formal analysis, Methodology, Visualization, Writing-original draft; MGL: Data curation, Investigation, Formal analysis, Methodology; ABF: Data curation, Investigation, Formal analysis, Methodology; AMD: Data curation, Investigation, Formal analysis, Methodology; PAB: Conceptualization, Formal analysis, Funding acquisition, Methodology, Resources, Supervision, Visualization, Writing-review \& editing JARG: Conceptualization, Formal analysis, Methodology, Visualization, Writing-review \& editing

Acknowledgments and Financial support: This work was supported by Fundação de Amparo à Pesquisa do Estado de São Paulo (2013/12486-5), Coordenação de Aperfeiçoamento de Pessoal de Nível Superior (CAPES) and Conselho Nacional de Desenvolvimento Científico e Tecnológico (CNPq, 465699/2014-6).

\section{Availability of data and material in:}

http://repositorio.unicamp.br/jspui/handle/REPOSIP/312739?mode=full http://repositorio.unicamp.br/jspui/bitstream/REPOSIP/312739/1/Grigoletti_GabrielBoerLima_M.p $\underline{\mathrm{df}}$

Competing interest: the authors declare no conflicts of interest, financial or otherwise. 


\section{ABSTRACT}

Background: Maternal undernutrition has been associated with psychiatric and neurological disorders characterized by learning and memory impairment. Considering the lack of evidence for this, we aimed to analyze the effects of gestational protein restriction on learning and memory function later in life. This research associates behavioral findings with hippocampal cell numbers and protein content related to neurodegenerative brain disease. Methods: Experiments were conducted in animals subjected to a low-protein (LP, 6\% casein) or regular-protein (NP, 17\% casein) diet throughout their pregnancy. Behavioral tests, isolated hippocampal isotropic fractionator cell studies, immunoblotting, and survival lifetime tests were performed. The results confirmed that the birthweight of LP male pups significantly reduced relative to NP male pups and that hippocampal mass increased in 88-week-old LP compared to age-matched NP offspring. We used the Morris water maze proximity measure, which is the sum of 10 distances each second between rat position and location of a hidden platform target, as a suitable test for assessing agerelated learning or memory impairment in aged offspring. Results: The results showed an increased proximity measure in 87-week-old LP rats $(52.6 \times 104 \pm 10.3 \times 104 \mathrm{~mm})$ as compared to NP rats (47.0 × $104 \pm 10.6 \times 103 \mathrm{~mm}, \mathrm{p}=0.0007)$. In addition, LP rats exhibited anxiety-like behaviors compared to NP rats at 48 and 86 weeks of life.

Additionally, the estimated neuron number was unaltered in LP rats; however, glial and other cell numbers increased in LP compared to NP rats. Here, we showed unprecedented hippocampal deposition of brain-derived neurotrophic factor, $\beta$-amyloid peptide $(\mathrm{A} \beta)$, and tau protein in 88 week-old LP compared to age-matched NP offspring. To date, no predicted studies showed changes in hippocampal neuron and glial cell numbers in maternal protein-restricted elderly offspring. The current data suggest that maternal protein restriction has a high impact on lifespan and brain structure, and function. Conclusion: the gestational protein restriction may accelerate hippocampal function loss, impacting learning/memory performance, and supposedly developing diseases similar to Alzheimer's disease (AD) in elderly offspring. Thus, we propose that maternal protein restriction could be a probable, elegant, and novel method for constructing an AD-like model in adult male offspring.

Keywords: Fetal Programming, Alzheimer's Disease, Behavior and memory, Maternal protein restriction, Hippocampus, $\beta$-amyloid peptide, Tau protein. 


\section{INTRODUCTION}

In humans and animal models, increasing evidence supports the hypothesis that disturbances during critical periods of fetal development may determine structural and functional alterations later in organs and systems, thereby predisposing individuals to metabolic, cardiovascular, and psychiatric diseases in adulthood [1-6]. As shown in several experimental models, gestational psychological, and nutritional stresses are involved in fetal programming [7-12].

In the embryonic phase, both cell proliferation and the differentiation of vital organs and neural connections are successfully achieved with maternal nutrition. Many neuroanatomical studies investigating the effects of prenatal malnutrition have found decreased neuronal body size, loss of neurons, reduced apical dendrites, branching, and reduced spine density in the hippocampus CA3 pyramidal cell layer [13-16]. Besides, considerable losses of neurons and synaptic ends [17] lead to progressive and, consequently, functional memory loss.

The hippocampus is a brain structure known to be related to emotional behavior; it is crucial for specialized learning and the process of forming memories. In addition, although hippocampal synaptic plasticity is involved in these functions, the details of this slight modulation are not entirely understood [18]. Alzheimer's Disease (AD) presents specific pathological brain hallmarks represented by extracellular deposition of the $\beta$-amyloid peptide (A $\beta)$ aggregates in senile plaques and neurofibrillary tangles (NFT) from excessive tau phosphorylation in different regions of the brain, including the hippocampus.

In human studies, during World War II (1944-1945), the Dutch famine showed a possible relationship between persons exposed to famine during the second trimester and affective psychosis, lending plausibility to reports associating affective psychoses with prenatal exposure [19]. As another critical moment of recent human exposure during gestation to undernutrition, the Chinese famine period, lasting more than three years (1959-1961), promoted a significant incidence of lower cognitive performance and brain development and mental disorders in adulthood [20]. Thus, a low intrauterine nutritional environment has been associated with severe psychiatric and neurological disorders characterized by learning and memory dysfunction, schizophrenia, autism, and neurodegenerative diseases [21].

These relevant neuropsychological disorders have led researchers to develop genetically modified animals that could rescue the disease's main characteristics and non-genetically modified animals, 
complementing these models. Considering the lack of evidence, we aimed to analyze the effects of gestational protein restriction (LP) offspring compared to regular protein intake age-matched progeny (NP) on learning and memory functions later in life. In addition to behavioral tests, isotropic fractionator study was performed to evaluate the hippocampal cell number and immunoblotting to determine the content of AD development-related proteins in gestational proteinrestricted elderly male offspring.

\section{MATERIALS AND METHODOLOGY}

\section{Animals}

Experiments were conducted on age-matched sibling-mated Wistar HanUnib rats (250-300 g). General guidelines established by the Brazilian College of Animal Experimentation (COBEA) and approved by the Institutional Ethics Committee (CEUA/UNICAMP \#3655-1) were followed throughout the study. Our local colonies originated from breeding stock supplied by CEMIB/UNICAMP, Campinas, SP, Brazil. Immediately after weaning at 3 weeks of age, animals were maintained under controlled temperature $\left(25^{\circ} \mathrm{C}\right)$ and lighting conditions $(08: 00-18: 00 \mathrm{~h})$, with ad libitum access to tap water and standard rodent laboratory chow (Nuvital, Curitiba, PR, Brazil); rats were raised up to 12 weeks of age.

Dams were maintained in an isocaloric standard rodent laboratory with ad libitum access to either regular protein content $(\mathrm{NP})(17 \%$ protein, $\mathrm{n}=20)$ or low protein content $(\mathrm{LP})(6 \%$ protein, $\mathrm{n}=20)$ chow for the duration of their pregnancy (Table 1).

At the time rats were placed to mate, sperm in the vaginal smear was designated as day 1 of pregnancy. Dams were kept in individual metabolic cages and weighed during pregnancy. Bodyweight, food consumption, and protein consumption were determined daily, and from these values, the weekly average was recorded once a week for each pregnant dam. Protein intake for each week was calculated by considering the total food intake and protein content of each diet.

On the day of birth, male offspring were weighed; only eight pups were kept per female. All groups returned to NP chow intake after delivery. We studied male LP offspring between 48 and 88 weeks of age, comparing them to age-matched NP offspring for analysis. An animals' survival lifetime in both groups (NP; $n=21$ and LP; $n=18$ ) was established as the spontaneous death of offspring in their previously defined housing.

\section{Behavioral analysis}

Male offspring from each litter, NP $(n=20)$ and LP $(n=20)$ groups, were used for behavioral research. All behavioral tests were performed during the light cycle. Test room illumination was kept constant and controlled under low-intensity white lighting (5-30 lux). 


\section{2.a. Morris water maze (MWM)}

All-cognitive performance analysis was conducted using the MWM test, a spatial learning test for rodents [22]. The test was performed with NP and LP offspring at 48 and 50 weeks and between 86 and 88 weeks of age ( $\mathrm{n}=20$ for each group) by a trained observer in a blinded fashion, as previously described [22]. Behavioral tests were performed in a circular black tank (170-cm diameter) filled to a depth of $31 \mathrm{~cm}$ at $22^{\circ} \mathrm{C}$ and placed in a dimly lit room with extrinsic clues. The tank was divided into imaginary quadrants, with a black platform (12-cm diameter, 30-cm height) placed in one.

\section{2.b. Working memory task}

A test described by Kesner et al. (2000) was used to test prefrontal cortex (PFC) function. This test aimed to assess the ability of a rat to learn the position of a hidden platform and to retain this information during four consecutive trials [23]. The working memory test consisted of 4 days of acquisition, with four trials per day. On each trial day, the position of the platform was kept constant; however, its position was varied on each successive day such that all four quadrants were used. Rats were placed facing the wall of the maze at a different starting point, north $(\mathrm{N})$, east $(\mathrm{E})$, south (S), or west (W), at the start of each daily trial. A trial was considered complete when the rat escaped onto the platform. When this escape failed to occur within $120 \mathrm{~s}$, the animal was gently guided to the platform. Rats were allowed to spend $30 \mathrm{~s}$ on the escape platform before being positioned at a new starting point. Escape latency, defined as the time (in seconds) spent to reach the platform, was recorded in each consecutive trial and expressed as the mean of each trial day.

2.c. Reference memory task

Morris (1984) described the reference memory test used to assess hippocampal function. This test aimed to evaluate the ability of a rat to learn the position of a hidden platform and retain this information during all test days [22]. The test consisted of 4 days of acquisition, with four trials per day. During the 4 days, the platform remained in the same quadrant. Rats were placed facing the wall of the maze at a different starting point, N, E, S, or W, at the start of each of the four daily trials. The trial ended when the rat escaped onto the platform. When this escape failed to occur within $120 \mathrm{~s}$, the animal was gently guided to the platform. Rats were allowed to spend $30 \mathrm{~s}$ on the escape platform before being positioned at a new starting point. The representative steeper curve of the time (in seconds) spent to reach the platform (escape latency) was recorded in consecutive trials and expressed as the mean of each trial day. 


\section{2.d. MWM proximity measure}

The test was performed in LP $(n=10)$ and age-matched NP $(n=10)$ offspring between 86 and 88 weeks of age. The animals were trained using a standardized procedure that required distal cues in the maze environment to learn the position of a hidden escape platform [24]. Briefly, rats were tested for four trials per day, with inter-trial delays of $30 \mathrm{sec}$, for a total of four consecutive days. The platform's location remained constant, and on each training trial, animals swam for $120 \mathrm{sec}$ or until they found the platform. Across trials, the starting location varied among four equidistant points around the perimeter of the apparatus. Every fourth trial was a probe test during which the platform was retracted to the pool's bottom. Probe trial performance provides an assessment of the search strategies used to navigate the maze [24]. Spatial behavior was recorded throughout training using a video tracking system designed for this purpose (Institute of Computing, Unicamp, SP, Brazil). The status of spatial learning was evaluated during each probe trial. The rat's distance from the escape platform was sampled 10 times per sec, and these values were averaged in 1-sec bins. Cumulative search error was then calculated as the summed 1-sec averages of this proximity measure corrected for each trial's particular start location (in $\mathrm{mm}$ ). This measure reflects the average proximity during probe trials relative to the escape platform's training location; lower index scores indicate a more accurate search focused on the target location. Previous research demonstrates that these measures are especially useful for distinguishing spatial learning impairments from other age-related performance deficits that are presumably independent of hippocampal function [24].

\section{2.e. Elevated plus maze (EPM)}

Next, 48 to 50 and 86 to 88 -week-old LP and NP offspring $(\mathrm{n}=20)$ were tested for 5 min in an EPM, a 72-cm high white polypropylene "plus"-shaped maze (ENV-560; Insight Equipment Ltd, Ribeirão Preto, SP, Brazil). The maze consisted of two facing open arms $(50.8 \times 10.2 \mathrm{~cm})$ and two closed arms $(50.8 \times 10.2 \times 40.6 \mathrm{~cm})$. The time spent in the open arms, junction area, and closed arms and the number of entrances and explorations in each section, were recorded using a system of infrared photo beams, with the crossings monitored using a computer. The duration spent in each EPM compartment was presented as a percentage of the trial's total duration.

\section{Isotropic fractionator study}

Hippocampal cells from NP and LP offspring were quantified using a technique previously described by Herculano-Houzel and Lent (2005) [25]. Briefly, following behavioral tests, sacrificed 88 week-old NP $(n=5)$ and age-matched LP $(n=5)$ offspring were perfused with saline, followed by $4 \%$ buffered paraformaldehyde, using cardiac puncture. Next, hippocampi were rapidly dissected 
on ice under a stereomicroscope; anatomical landmarks were observed according to Paxinos and Watson (2005) using a standardized technique widely used by the Life and Health Sciences Research Institute (ICVS), School of Health Sciences, University of Minho, Braga, Portugal. Following isolation of the left hippocampus, a suspension of nuclei was obtained through mechanical dissociation in a standard solution ( $40 \mathrm{mM}$ sodium citrate and $1 \%$ Triton $\mathrm{X}-100$ ) in a 40-mL glass Tenbroeck tissue homogenizer.

Complete homogenization was achieved using at least $1 \mathrm{~mL}$ of dissociation solution per $100 \mathrm{mg}$ of brain tissue and by grinding until the smallest visible fragments were dissolved. The homogenate was collected using a Pasteur pipette and transferred to $15-\mathrm{mL}$ centrifuge tubes. The grinding pestle and tube were washed several times with dissociation solution, and the sample was centrifuged for $10 \mathrm{~min}$ at $4000 \times \mathrm{g}$. Pelleted nuclei were then suspended in phosphate-buffered saline (PBS) containing 1\% 4',6-diamidino-2-phenylindole (DAPI) (Molecular Probes, Eugene, OR, USA) to make all nuclei visible under ultraviolet illumination. After sufficient agitation, 5- $\mu \mathrm{L}$ aliquots were used to determine nuclei density using a hemocytometer. The DAPI-stained nuclei were counted under a fluorescence Olympus microscope at 400× magnification.

Once the nuclear density in the suspension was determined by averaging at least eight samples, the total number of cells in the original tissue was estimated by multiplying the mean nuclear density by the total suspension volume.

To estimate the total neuron number, a $200-500-\mu \mathrm{L}$ aliquot of nuclear suspension was immunoreacted for NeuN. Nuclei in the aliquot were collected using centrifugation, resuspended in a $0.2 \mathrm{M}$ solution of boric acid $(\mathrm{pH} 9.0)$, and heated for $1 \mathrm{~h}$ at $75^{\circ} \mathrm{C}$ for epitope retrieval. Subsequently, nuclei were again collected using 6000xg centrifugation, washed in PBS, and incubated overnight at room temperature with anti-NeuN mouse antibody (1:300 in PBS; Chemicon, Temecula, CA, USA).

The nuclei pool was washed in PBS and incubated in cyanine 3-conjugated goat anti-mouse IgG secondary antibody (1:400 in 40\% PBS, 10\% goat serum, and 50\% DAPI; Accurate Chemicals, Westbury, NY, USA) for $2 \mathrm{~h}$. Next, the centrifugation-collected nuclei were washed and resuspended in PBS prior to counting under a fluorescence microscope. The total number of nonneuronal nuclei was calculated by subtracting the number of NeuN-containing nuclei from the total number of nuclei.

\section{Immunoblotting}

Eighty-eight-week-old NP ( $n=5)$ and age-matched LP $(n=5)$ offspring were anesthetized and their hippocampus isolated in ice-cold buffer for analysis. The Bradford method was used for protein 
quantification in tissue extracts. For immunoblotting of total protein, extracts were loaded onto an SDS-PAGE electrophoresis gel. Briefly, equal amounts of protein $(20 \mu \mathrm{g})$ from hippocampal samples were denatured in Laemmli buffer $(100 \mathrm{mmol} / \mathrm{L} \mathrm{DTT})$, incubated at $95^{\circ} \mathrm{C}$ for $4 \mathrm{~min}$, and electrophoresed on an $8 \%$ SDS-PAGE gel. Proteins were transferred from the gel to nitrocellulose membranes for $90 \mathrm{~min}$ at $120 \mathrm{~V}$ (constant) using a Bio-Rad miniature transfer apparatus (MiniProtean, Bio-Rad).

Non-specific protein binding to the nitrocellulose was reduced by preincubating the filter for $2 \mathrm{~h}$ at $22^{\circ} \mathrm{C}$ in blocking buffer $(5 \%$ non-fat dry milk, $10 \mathrm{mmol} / \mathrm{L}$ Tris, $150 \mathrm{mmol} / \mathrm{L} \mathrm{NaCl}$, and $0.02 \%$ Tween 20) [26]. Nitrocellulose blots were incubated at $4^{\circ} \mathrm{C}$ overnight with specific antibodies against IGFR1 (Ab90657; Abcam, Cambridge, UK, dilution, 1:1000), ERK2 (sc154; Santa Cruz Biotech, Inc., Santa Cruz, CA, USA, dilution, 1:1000), pPI3K (cs4228S; Cell Signaling Technology, Danvers, MA, USA, dilution, 1:1000), brain-derived neurotrophic factor (BDNF) (sc546; Santa Cruz Biotech, Inc., dilution, 1:1000), Tau (sc5587; Santa Cruz Biotech, Inc., dilution, 1:1000), pTau (sc16945; Santa Cruz Biotech, Inc., dilution, 1:1000), A $\beta$ (sc 374527; Santa Cruz Biotech, Inc., dilution, 1:1000), HSP70 (sc3575; Santa Cruz Biotech, Inc., dilution, 1:1000), and HSP90 (sc7947; Santa Cruz Biotech, Inc., dilution, 1:1000).

Membranes were subsequently incubated with peroxidase-conjugated secondary antibodies (1:10.000). Bands were detected using chemiluminescence (RPN 2108 ECL; Amersham Pharmacia Biotech, Piscataway, NJ, USA); density was quantified using the optical method (Scion Image 4.0.3.2 software; ScionCorp, Frederick, MD, USA). Images of developed radiographs were scanned (Epson Stylus 3500), and band intensities quantified using optical densitometry (Scion Image Corporation). Membranes were stained with $\alpha$-tubulin (cs2144S; Cell Signaling Technology, dilution, 1:1000) or reversible Ponceau to discard any possible inequalities in protein loading and transfer in the western blots. Only homogeneously stained membranes were used in this study.

\section{Data presentation and statistical analysis}

All data were reported as mean \pm standard error of the mean (SEM). Data obtained over time were analyzed using one-way analysis of variance (ANOVA). When one-way ANOVA analysis indicated statistical differences between groups, post-hoc comparisons between means were performed using Bonferroni's contrast test. Comparisons between two groups were performed using a two-way repeated measure ANOVA, in which the first factor was protein content in a dam's diet, and the second factor was time. When the interaction was significant, mean values were compared using Tukey's post-hoc analysis. Student's $t$-tests were used to evaluate studies involving only two independent samples, within or between groups. Welch's test was used to correct situations 
characterized by heteroscedasticity (different variances between groups). An animal's survival lifetime was assessed using Mantel-Cox and Gehan-Breslow-Wilcoxon tests. GraphPad Prism 5.00 was used for data analysis (GraphPad Software, Inc., La Jolla, CA, USA). The level of significance was set at $\mathrm{p} \leq 0.05$.

\section{RESULTS}

\section{A gestational low-protein diet affects birthweight and the hippocampal mass}

Although body mass of LP male pups at birth was significantly reduced, compared to NP progeny (NP: $6 \pm 0.05 \mathrm{~g}, \mathrm{n}=20$ vs. LP: $5.8 \pm 0.05 \mathrm{~g}, \mathrm{n}=20, \mathrm{p}=0.006$, Figures $1 \mathrm{~A}$ and S1); after 7 days of delivery, the LP and NP offspring body mass are similar, and this similarity persisted unchanged until week 88 of follow-up. (Figure 1C-E). Brain and hippocampal masses did not differ between 50-week-old LP $(\mathrm{n}=5)$ and NP offspring $(\mathrm{n}=5$, Figure S2). However, in 88-week-old LP, the relative hippocampus body $(\mathrm{H} / \mathrm{bd})$ or brain $(\mathrm{H} / \mathrm{br})$ mass ratios were significantly enhanced relative to an age-matched NP hippocampal mass (H/bd, LP: $0.03 \pm 0.004$ vs. NP: $0.01 \pm 0.001, \mathrm{n}=5, \mathrm{p}=$ 0.03 and H/br, LP: $0.06 \pm 0.005$ vs. NP: $0.04 \pm 0.006, \mathrm{n}=5, \mathrm{p}=0.01$, Figure 1C-E, bottom Panels). Dams on the LP diet during pregnancy were lighter in the second $(238.13 \pm 6.0 \mathrm{~g})$ and third (325.1 $\pm 6.6 \mathrm{~g}$ ) weeks of pregnancy as compared to those on the NP (2nd week: $244.7 \pm 8 \mathrm{~g}$ and 3rd week: $354.7 \pm 8 \mathrm{~g}$ ) diet, despite having an equal body weight in the first week of pregnancy (diet vs. time $p<0.001$; diet $p=0.007$; time $p<0.001$ ). Thus, considering the entire pregnancy, dams in the LP group had lower weight gain than those in the NP group (NP [n=20]: $109.86 \pm 20.04 \mathrm{~g}$; LP [n $=$ 20]: $87.00 \pm 14.01 \mathrm{~g} ; \mathrm{p}<0.001)$. Weekly food intake was higher in LP dams in the first two weeks of pregnancy (1st week: $129.2 \pm 3.25 \mathrm{~g}$ and 2 nd week: $135.7 \pm 6 \mathrm{~g}$ ) compared to NP (1st week: $111.1 \pm 3.95 \mathrm{~g}$ and 2 nd week: $119.4 \pm 6 \mathrm{~g}$ ) dams (diet vs. time $\mathrm{p}=0.018$; diet $\mathrm{p}<0.001$; time $\mathrm{p}<$ 0.118). However, there was no difference in food intake between the groups in the last week of pregnancy (NP: $122.94 \pm 3.95 \mathrm{~g}$ vs. LP: $122.9 \pm 6 \mathrm{~g})$. Litter sizes were similar $(\mathrm{p}=0.239)$ between rats fed an LP diet $(n=10.67 \pm 2.44$ puppies $)$ and those fed an NP diet $(n=11.43 \pm 1.94$ puppies $)$. The weekly assessment of protein intake showed that dams from the LP group were exposed to severe protein intake restriction (NP: $20.01 \pm 0.9 \mathrm{~g}$ vs. LP: $7.91 \pm 0.7 \mathrm{~g}$ ) during the entire pregnancy (diet vs. time $\mathrm{p}=0.018$; diet $\mathrm{p}<0.001 ;$ time $\mathrm{p}=0.069$ ).

\section{Morris Water Maze (MWM)}

2.a. Working memory - Working memory, as estimated via escape latency, was not statistically different in 46 and 86-week-old LP as compared to age-matched NP offspring (49-week old, n = 20, 
$\mathrm{p}=0.87$, or 87 -week old, $\mathrm{n}=20, \mathrm{p}=0.078$ ) (Figure 2). These results suggest the same learning response in both experimental groups.

2.b. Reference memory - Hippocampal reference memory significantly reduced in 49-week-old LP rats as compared to NP offspring $(\mathrm{p}=0.0372)$. These animals spent substantially more time finding the hidden platform (latency) than their age-matched NP offspring. When comparing day 4 and 7 trials, reduced latency (learning capacity) was observed only in NP $(n=20, p=0.046)$ as compared to LP offspring ( $\mathrm{n}=20, \mathrm{p}=0.08$, Figure 2$)$. However, in the 87-week-old offspring analysis, no reference memory differences were observed in either group.

2.c. Proximity measure - The rat's distance from the escape platform was sampled 10 times per sec, and these values were averaged in 1-sec bins. An elevated cumulative search error, calculated as the summed 1-sec averages of this proximity measure corrected for each trial's particular start location (in mm), was observed in 87-week-old LP as compared to NP rats (LP: $52.6 \times 104 \pm 10.3$ $\times 104 \mathrm{~mm} v s . \mathrm{NP}: 47.0 \times 104 \pm 10.6 \times 103 \mathrm{~mm}, \mathrm{p}=0.0007 ; \mathrm{n}=10$ for each group, Figure. 3 )

\section{EPM}

The gestational protein-restricted diet triggered anxiety-related behaviors in adult offspring as compared to NP adult progeny at both 48 and 86 weeks of life. The time spent in each EPM compartment was presented as a percentage of the trial's total duration. The results showed a significant reduction in the time spent in open arms (in \%) in 48 (NP: $15.78 \pm 5.749 \%$ vs. LP: 3.321 $\pm 1.512 \%, \mathrm{p}=0.0348, \mathrm{n}=8)$ and $86(\mathrm{NP}: 37.55 \pm 14.55 \%$ vs. LP: $7.171 \pm 3.357 \%, \mathrm{p}=0.0388, \mathrm{n}=$ 8, Figure 3) week-old LP compared with age-matched NP offspring.

\section{Quantification of total cells and neurons in the hippocampus}

Total cell number was significantly enhanced in the hippocampus of LP as compared to NP rats (LP: $15.98 \times 10^{6} \pm 17.69 \times 10^{5}$ vs. NP: $12.56 \times 10^{6} \pm 33.85 \times 10^{4}, \mathrm{p}=0.047, \mathrm{n}=8$ for each group, Figure 6). The estimated number of neurons was unaltered in LP as compared to NP offspring. However, glial cell numbers were enhanced in LP as compared to NP offspring (LP: $13.91 \times 10^{6} \pm$ $11.66 \times 10^{6} v s . \mathrm{NP}: 10.58 \times 10^{6} \pm 30.03 \times 10^{4}, \mathrm{p}=0.04$, Figure 4).

\section{Immunoblotting}

Whole hippocampal protein levels were assessed in 88 week-old NP compared to age-matched LP offspring using immunoblotting comparative analysis. The results revealed $61 \%$ enhanced BDNF mature protein levels in LP compared to NP offspring $(n=5$ for each group, $\mathrm{p}=0.0413$; Figure 5). Similarly, whole hippocampal extracts showed increased tau, tau phosphorylation $(48 \%, \mathrm{n}=5, \mathrm{p}=$ 
0.0397), and $\mathrm{A} \beta(77 \%, \mathrm{n}=5, \mathrm{p}=0.0365)$ protein levels in LP compared to age-matched NP offspring. However, stress-related proteins (HSP70 and HSP90), IGFR1, pPI3K, and ERK2 were unchanged between both groups (Figure 5).

\section{Survival curve}

The survival lifetime of animals, as evaluated using Mantel-Cox and Gehan-Breslow-Wilcoxon tests, demonstrated a significant reduction $(\mathrm{p}<0.001)$ in the life span of LP $(n=18)$ as compared to NP rats $(n=21)$. The estimated median survival time of NP and LP rats was 120 weeks and 108 weeks, respectively. These results showed a significant reduction in survival time in LP as compared to NP offspring (Figure 6).

\section{DISCUSSION}

Studies have demonstrated that disturbances during crucial fetal developmental periods may determine morphological and functional changes in organs and systems [1-6]. Brain development is sensitive to gestational programming, and humoral factors, such as angiotensin, steroids and their receptors, transcriptional factors, and nutritional availability, permanently affect neural ontogenesis $[27,28]$. Among neural structures, the hippocampus has been demonstrated to be particularly susceptible to the programming effects of gestational emotional and nutritional stressors [for a review, see 29].

The present study confirms previous data demonstrating that gestational protein restriction leads to low birth weight and catch-up growth phenomena in rodents. This effect leads to gender-related disorders in blood pressure, glucose metabolism, and anxiety-like behaviors in male adult progeny compared to female offspring [30,31]. Sex hormones determine phenotypic dimorphism in an adult fetal-programmed disease model by modulating regulatory pathways critical for the long-term control of neural, cardiac, and endocrine functions.

Specific hormones and the estrus cycle may interfere with behavioral, hemodynamic, and systemic water and ion homeostasis in female rodents. Thus, considering the above findings and the influence of gender on physiological responses, this study was performed in male rats. However, additional research with long-term follow-up and cross-fostering, including behavioral tests in female offspring, would help specify the nature of some protein-restriction effects. Our previous results sought to elucidate the underlying mechanisms of fetal programming [11,12,15,32-37]. The present study confirms that reduced fetal birth weight in LP offspring may reflect the influence of inappropriate protein intake on healthy embryo growth and development during pregnancy. 
As mentioned above, after the second week of age, LP offspring's body mass was similar to that observed in the NP group, a phenomenon known as catch-up growth. Also, the brain weights of 50 and 88-week-old LP rats were the same as that for age-matched NP offspring. However, in 88week-old LP rats, the hippocampus weight by body or brain mass ratio was significantly enhanced as compared to age-matched NP hippocampal ratio masses. Additionally, an 88-week-old LP hippocampi cell study using the isotropic fractionator technique showed an increased number of glial and other non-neuronal cells; the neuron number was not otherwise altered as compared to age-matched NP offspring.

Previous studies investigating the effects of maternal undernutrition on brain structure have demonstrated loss of neurons [14], decreased neuronal body size and length of apical dendrites, branching [15,35,38], and reduced CA1 hippocampal subfield pyramidal cell spine density [39]. These studies have also shown dentate gyrus and decreases in the somatic axis and the number of dendritic branches and spines $[15,38,40]$. However, to the best of our knowledge, no predicted studies have evaluated changes in the hippocampal number and type of cells in severe maternal protein-restricted offspring.

Previous studies have demonstrated that several functional neural disorders may result from substantial glial proliferation, which can occur to differing extents in specific brain regions [41]. As reactive gliosis is a hallmark of $\mathrm{AD}$, we may infer that an increased number of hippocampal glial cells may be associated with structural and functional disorders in this neurodegenerative rodent model $[42,43]$. Herein, hippocampi homogenate was processed following vigorous whole-brain saline perfusion to minimize contamination with peripheral cells. However, we cannot exclude a potential contribution from infiltrating cells once the blood-brain barrier is compromised during Alzheimer-like disease [44-46].

We hypothesize that hippocampi with enhanced glial cells may have potential roles in the spread of tau pathology [47], synapse loss [48], and neuronal dysfunction through the release of proinflammatory factors [49,50]. In 1907, Alzheimer himself described reactive glial cells in neuritic plaques [51]. A recent study confirmed the presence of reactive astrocytes and microglia in the vicinity of $\mathrm{A} \beta$ deposits [52], both of which are associated with neuroinflammation and $\mathrm{AD}$ evolution. Although the role of glial cell participation is unclear, the high number of hippocampal non-neuronal cells strongly suggests a causal nexus despite conflicting reports regarding their detrimental or protective contribution to AD pathogenesis [53].

However, emerging studies report a loss of oligodendrocyte lineage cells in gray matter, presumably associated with amyloid plaque deposition, oxidative stress, and apoptosis [54-56]. An accurate understanding of the role of astrocytes in AD remains unclear. Considering the present 
model's findings, we hypothesize that glial cells may play a critical role in dementia processes, likely through microglial activation. Further studies on cellular composition are essential to better understand hippocampal contributions to pathological behavior manifestations.

The present study evaluated whether gestational protein-restricted intake is associated with hippocampal molecular changes and, if so, aimed to explain the functional disorder in aging male LP progeny. In addition, to the best of our knowledge, this study is the first to show a significant enhancement of hippocampal $\mathrm{A} \beta$ deposition in maternal protein-restricted 88-wk-old offspring.

Although increased tau and $\mathrm{A} \beta$ deposition was consistently demonstrated in the 88-week-old LP hippocampus as compared to age-matched NP offspring, stress-related proteins, HSP70 and HSP90, were unchanged in both groups. Typical AD-associated structural brain abnormalities are characterized by senile plaques and NFT, which are complexes of paired helical microtubuleprotein tau filaments associated with toxic $A \beta$ oligomer deposition, resulting from $A \beta$ monomer self-association [57-59]. Prior research has demonstrated that $A \beta$ monomers are naturally produced and secreted at the synaptic cleft; $A \beta$ monomers appear to be necessary for neuronal survival, given that $A \beta$ production inhibition is associated with cultured neuronal death [60].

The present study showed that, despite enhanced hippocampal deposition of $A \beta$ oligomers in maternal protein-restricted adult offspring, the hippocampus presented a significant increase in BDNF expression. BDNF is significant for maintaining the development and survival of neurons in the brain. Considering primary data, BDNF may be essential for maintaining viable cortical neurons, whose early dysfunction contributes to short-term memory loss [61].

However, if and how glial dysfunction is involved in changes to hippocampal circuitry and its contribution to learning and memory disorders remain unknown. Herein, using the MWM test, we assessed learning and memory in gestational protein-restricted and NP progeny, finding significant differences in working memory responses, as characterized by enhanced escape latency in 49-weekold LP as compared to age-matched NP offspring, but not in older offspring.

However, a highly sensitive assessment of age-related learning/memory impairment in aged rats was performed using proximity measure distances [24], which increased in 86-week-old LP, as compared to age-matched NP offspring. In the current study, proximity measures were useful for associative analyses, taking into account changes in hippocampal neurocytology, abnormal protein deposition, and LP offspring's functional decline. These data suggest that the hippocampal referential memory process in LP offspring might be altered by maternal protein restriction, particularly in elderly rats.

Also, LP offspring were found to spend less time in EPM open arm compartments, resulting in an extended stay in the device's closed arms, as presented via percentages of the trial's total duration. 
These results revealed an anxiety-like behavioral phenotype in 88-week-old LP as compared to agematched NP offspring. The current study sought to explore the relationship between elevated hippocampal mass, potentially via increases in glial and other non-neuronal cells, and anxiety-like behavior in 88-week-old LP rat progeny. Conversely, in human studies, patients with depression and previous depression-induced animal models have demonstrated a negative relationship between hippocampal volume/mass and trait anxiety $[62,63]$.

However, the present study was unable to exclude the contribution of several brain regions in rodent anxiety-like behavior as well as possible confounds arising from the segregation of other behavioral disorders. Considering the above findings, we suppose that enhanced BDNF in 88-week-old LP offspring is a final attempt to maintain hippocampal functionality and protect it from further damage. Within this scenario, elevated hippocampal BDNF levels may restrain neuron loss, at least temporarily, even reducing partially hippocampal dysfunction previously altered in 49-week-old LP offspring.

Preliminary data have shown the involvement of hippocampal molecular pathways, such as $\mathrm{PI} 3 \mathrm{~K} / \mathrm{AKT}$, by recruiting IGF-IRs and increasing CREB expression via $\mathrm{A} \beta$ monomer stimulation during increased transcription and release of BDNF [63-65]. We could not demonstrate any change in IGF-IR and PI3K phosphorylation in the current study, suggesting that BDNF may be expressed via different mechanisms [53]. Recent studies have also indicated that tau protein is a crucial factor underlying $\mathrm{AD}$ development and progression. The present model confirmed such findings, with increased hippocampal tau expression accompanying 28\% enhancement in phosphorylated tau in 88-week-old LP as compared to age-matched NP rats. The vast majority of AD experimental models almost exclusively consist of transgenic mice expressing human genes, resulting in amyloid plaques and NFT [66-68]. Other models have included invertebrate animals such as Drosophila melanogaster and vertebrates such as zebrafish. Considering the reduced relatedness in physiology between humans and these models, the latter is less extensively studied. [69,70].

Finding a naturally occurring $\mathrm{AD}$ model is appealing, as it would likely represent changes in human AD more accurately. Prior studies have demonstrated that gestational protein restriction leads to severe physiological and morphological changes in neurons [31,71-74] in addition to behavioral changes $[75,76]$ and delays in cognitive and intellectual functions $[77,78]$. Thus, our results indicate that exposing the rat fetus to gestational protein restriction was sufficient to cause enhanced $\mathrm{A} \beta$ and tau protein hippocampal deposition in 88-week-old LP as compared to age-matched NP offspring.

Furthermore, changes in the cell numbers were observed, accompanied by hippocampal-dependent memory perturbations in LP progeny early than in control offspring. We suggest that these neural disorders may be key in causing the cognitive decline in early-stage AD-like rodent models. 
Besides, consistent with previous studies, LP offspring significantly reduced lifespan (approximately 12 weeks) compared to NP offspring [79-81]. Incidentally, studies investigating the relationship among influence at the beginning of the developmental phase, fetal programming, and shortening of telomeres found each of these were strongly associated with perinatal stressors such as maternal stress, maternal food restriction, and maternal overnutrition [69-72].

Aging is characterized by a progressive loss of physiological integrity, leading to impaired function and increased vulnerability to death. Thus, comprehensive hallmarks of aging, including genomic instability, telomere attrition, epigenetic alterations, nutrient sensing, mitochondrial dysfunction, cellular senescence, stem cell exhaustion, and altered cellular communication, must be further investigated in this programmed experimental model. The current data suggest a high impact of maternal protein restriction on progeny lifespan and hippocampus structure, significantly accelerating the loss of hippocampal function, impacting learning/memory performance, and supposedly developing neurodegenerative-like syndromes in 88-week-old LP murine offspring. Carefully, we can suppose that maternal protein restriction in rats may be a probable, elegant, and novel method for constructing an AD-like model in adult male offspring.

\section{REFERENCES}

1. Ashton N, (2000), Perinatal development and adult blood pressure. Braz J Med Biol Res 33, 731740.

2. Barker DJ, (1998), In utero programming of chronic disease. Clinical Science 95, 115-128.

3. O'Regan D, Kenyon CJ, Seckl JR, Holmes MC, (2004), Glucocorticoid exposure in late gestation in the rat permanently programs gender-specific differences in adult cardiovascular and metabolic physiology. American Journal of Physiology-Endocrinology and Metabolism 287, 863-870.

4. Plagemann A, (2004), 'Fetal programming' and 'functional teratogenesis': on epigenetic mechanisms and prevention of perinatally acquired lasting health risks. Journal of Perinatal Medicine 32, 297-305.

5. Seckl JR, Meaney MJ, (2004), Glucocorticoid programming. Annals of the New York Academy of Sciences 1032, 63-84. 
6. Lesage J, Sebaai N, Leonhardt M, Dutriez-Casteloot I, Breton C, Deloof S, Vieau D, (2006), Perinatal maternal undernutrition programs the offspring hypothalamus-pituitary-adrenal (HPA) axis. Stress 9, 183-198.

7. Persson E, Jansson T, (1992), Low birth weight is associated with elevated adult blood pressure in the chronically catheterized guinea-pig. Acta Physiol Scand 145, 195-196.

8. Woodall SM, Johnston BM, Breier BH, Gluckman PD, (1996), Chronic maternal undernutrition in the rat leads to delayed postnatal growth and elevated blood pressure of offspring. Pediatric Res $40,438-443$.

9. Godfrey K, Robinson S, Barker DJ, Osmond C, Cox V, (1996), Maternal nutrition in early and late pregnancy concerning placental and fetal growth. British Med J 17, 410-414.

10. Langley-Evans SC, Welham SJ, Sherman RC, Jackson AA, (1996), Weanling rats exposed to maternal low-protein diets during discrete periods of gestation exhibit differing severity hypertension. Clin Sci 91, 607-615.

11. Mesquita FF, Gontijo JAR, Boer PA, (2010a), Expression of renin-angiotensin system signaling compounds in maternal protein-restricted rats: effect on renal sodium excretion and blood pressure. Nephrol Dial Transpl 25, 380-388.

12. Mesquita FF, Gontijo JAR, Boer PA, (2010b), Maternal undernutrition and the offspring kidney: from fetal to adult life. Braz J Med Biol Res 43, 1010-1018.

13. Diáz-Cintra S, Cintra L, Galván A, Aguilar A, Kemper T, Morgane PJ, (1991), Effects of prenatal protein deprivation on postnatal development of granule cells in the fascia dentata. $\mathbf{J}$ Comparative Neurol 310, 356-364.

14. Lister JP, Blatt GJ, DeBassio WA, Kemper TL, Tonkiss J, Galler JR, Rosene DL, (2005), Effect of prenatal protein malnutrition on numbers of neurons in the principal cell layers of the adult rat hippocampal formation. Hippocampus 15, 393-403. 
15. Lopes A, Torres DB, Rodrigues AJ, Cerqueira JJ, Pêgo JM, Sousa N, Gontijo JAR, Boer P A, (2013). Gestational protein restriction induces CA3 dendritic atrophy in dorsal hippocampal neurons but does not alter learning and memory performance in adult offspring. International Journal of Developmental Neuroscience, 31, 151-156

16. Grigoletti-Lima GB. (2015), Neurogênese e estrutura dendrítica hipocampais em ratos submetidos à restrição proteica durante a ontogênese encefálica: estudo comportamental e influências do ambiente enriquecido. Dissertação (mestrado) - Universidade Estadual de Campinas, Faculdade de Ciências Médicas, Campinas, SP. Available in: $<$ http://www.repositorio.unicamp.br/handle/REPOSIP/312739>.

17. Reitz C, Mayeux R. (2014) Alzheimer's disease: epidemiology, diagnostic criteria, risk factors, and biomarkers. Biochem Pharmacol. 88, 640-651. doi: 10.1016/j.bcp.2013.12.024.

18. Bannerman, D.M., Rawlins, J.N., McHugh, S.B., Deacon, R.M., Yee, B.K., Bast, T., Zhang, W.N., Pothuizen, H.H., Feldon, J., 2004. Regional dissociations within the hippocampus - memory and anxiety. Neuroscience and Biobehavioral Reviews 28, 273-283.

19. Brown AS, Susser ES, Lin SP, Neugebauer R, Gorman JM, (1995). Increased Risk of Affective Disorders in Males after Second Trimester Prenatal Exposure to the Dutch Hunger Winter of 194445. British J Psych, 166, 601-606.

20. Rong H, Lai X, Mahmoudi E, Fang H, (2019), Early-Life Exposure to the Chinese Famine and Risk of Cognitive Decline. J Clin Med. 8: 484-495. doi:10.3390/jcm8040484

21. Moody L, Chen H, Pan YX, (2017), Early-Life Nutritional Programming of Cognition-The Fundamental Role of Epigenetic Mechanisms in Mediating the Relation between Early-Life Environment and Learning and Memory Processes. Adv Nutr. 8: 337-350. doi:10.3945/an.116.014209

22. Morris R, (1984), Developments of a water-maze procedure for studying spatial learning in the rat. J Neurosci Meth 11, 47-60. 
23. Kesner RP, Gilbert PE, Wallenstein GV, (2000), Testing neural network models of memory with behavioral experiments. Current Opinion in Neurobiology 10, 260-265. Kesner, R.P., 2007. Behavioral functions of the CA3 subregion of the hippocampus. Learning and Memory 14, 771781.

24. Gallagher M, Burwell RD, Burchinal M, (2015), Severity of Spatial Learning Impairment in Aging: Development of a Learning Index for Performance in the Morris Water Maze. Behav Neurosci, 129: 540-548. doi:10.1037/bne0000080

25. Herculano-Houzel S, Lent R (2005) Isotropic fractionator: a simple, rapid method for the quantification of total cell and neuron numbers in the brain. J Neurosci 25, 2518-2521.

26. Sene LB, Rizzi VHG, Gontijo JAR, Boer PA, (2018), Gestational low-protein intake enhances whole-kidney miR-192 and miR-200 family expression and epithelial-to-mesenchymal transition in rat adult male offspring. J Exp Biol. 22, 221(Pt 10). pii: jeb171694. doi: 10.1242/jeb.171694..

27. Welberg L.A., Seckl J.R. (2001). Prenatal stress, glucocorticoids and the programming of the brain. J Neuroendocrinol, 13(2), 113-128.

28. Matsumoto A. (1991). Synaptogenic action of sex steroids in developing and adult neuroendocrine brain. Psychoneuroendocrinology, 16(1-3), 25-40.

29. Darnaudéry M., Maccari S. (2008). Epigenetic programming of the stress response in male and female rats by prenatal restraint stress. Brain Res Rev, 57(2), 571-585. doi: 10.1016/j.brainresrev.2007.11.004.

30. Ozaki T, Nishina H, Hanson MA, Poston L, (2001), Dietary restriction in pregnant rats causes gender-related hypertension and vascular dysfunction in offspring. J Physiol.530, 141-152.

31. Gillette R, Michael P. Reilly, Viktoria Y. Topper, Lindsay M. Thompson, David Crews, AC, (2017), Anxiety-like behaviors in adulthood are altered in male but not female rats exposed to low dosages of polychlorinated biphenyls in utero, Horm Behav. 87, 8-15. 
32. de Lima MC, Scabora JE, Lopes A, Mesquita FF, Torres D, Boer PA, Gontijo JA, (2012), Early changes of hypothalamic angiotensin II receptors expression in gestational protein-restricted offspring: effect on water intake, blood pressure, and renal sodium handling. J Renin Angiotensin Aldosterone Syst. 14, 271-82. doi: 10.1177/1470320312456328

33. Vaccari B, Mesquita FF, Gontijo JA, Boer, PA. (2015), Fetal kidney programming by severe food restriction: effects on structure, hormonal receptor expression, and urinary sodium excretion in rats. J Renin Angiotensin Aldosterone Syst. 16, 33-46. doi: 10.1177/1470320313481081.

34. Scabora JE, de Lima MC, Lopes A, de Lima IP, Mesquita FF, Torres DB, Boer PA, Gontijo JA, (2015), Impact of taurine supplementation on blood pressure in gestational protein-restricted offspring: Effect on the solitary medial tract nucleus cell numbers, angiotensin receptors, and renal sodium handling. J Renin Angiotensin Aldosterone Syst. 16, 47-58. doi: $10.1177 / 1470320313481255$.

35. Torres DB, Lopes A, Rodrigues AJ, Cerqueira JJ, Sousa N, Gontijo JAR, Boer PA, (2018) Anxiety-like behavior and structural changes of the bed nucleus of the stria terminalis (BNST) in gestational protein-restricted male offspring. J Dev Orig Health Dis. 9, 536-543. doi: 10.1017/S2040174418000399.

36. Custódio AH, de Lima MC, Vaccari B, Boer PA, Gontijo JAR (2017), Renal sodium handling and blood pressure changes in gestational protein-restricted offspring: Role of renal nerves and ganglia neurokinin expression. PLoS One. 20, e0179499. doi: 10.1371/journal.pone.0179499.

37. Assalin HB, Gontijo JAR, Boer PA, (2019), miRNAs, target genes expression, and morphological analysis on the heart in gestational protein-restricted offspring. PLoS One. 14, e0210454. doi: 10.1371/journal.pone.0210454.

38. Díaz-Cintra S, García-Ruiz M, Corkidi G, Cintra L, (1994), Effects of prenatal malnutrition and postnatal nutritional rehabilitation on CA3 hippocampal pyramidal cells in rats of four ages. Brain Res 662, 117-126. 
39. Cintra L, Granados L, Aguilar A., Kemper T, DeBassio W, Galler J, Morgane P, Durán P, DíazCintra S, (1997), Effects of prenatal protein malnutrition on mossy fibers of the hippocampal formation in rats of four age groups. Hippocampus 7, 184-191.

40. Cintra A, Solfrini V, Agnati LF, Gustafsson JA, Fuxe K, (1990), Strongly glucocorticoid receptor immunoreactive neurons in the neonatal rat brain. Neuroreport 2, 85-88.

41.44. Kamphuis W, Orre ML, Dahmen M, Hol EM, (2012) Differential cell proliferation in the cortex of the APPswePS1dE9 Alzheimer's disease mouse model. Glia 60, 615-629

42. Olmos-Alonso A, Schetters ST, Sri S, Askew K, Mancuso R, Vargas-Caballero, M, Holscher C, Perry VH, Gomez-Nicola D, (2016), Pharmacological targeting of CSF1R inhibits microglial proliferation and prevents the progression of Alzheimer's-like pathology. Brain 139, 891-907

43. Fan Z, Brooks DJ, Okello A, Edison P. (2017), An early and a late peak in microglial activation in Alzheimer's disease trajectory. Brain 140, 792-803

44. Liebner S, Dijkhuizen RM, Reiss Y, Plate KH, Agalliu D, Constantin G, (2018), Functional morphology of the blood-brain barrier in health and disease. Acta Neuropathol. 135, 311-336

45. Erickson MA, Banks WA, (2013), Blood-brain barrier dysfunction as a cause and consequence of Alzheimer's disease. J. Cereb. Blood Flow Metab. 33, 1500-1513

46. Montagne A, Barnes SR, Sweeney MD, Halliday MR, Sagare AP, Zhao Z, Toga AW, Jacobs RE, Liu CY, Amezcua L, Harrington MG, Chui HC, Law M, Zlokovic BV, (2015), Blood-brain barrier breakdown in the aging human hippocampus. Neuron 85, 296-302

47. Asai H, Ikezu S, Tsunoda S, Medalla M, Luebke J, Haydar T, Wolozin B, Butovsky O, Kugler S, Ikezu T, (2015), Depletion of microglia and inhibition of exosome synthesis halt tau propagation. Nat. Neurosci. 18, 1584-1593

48. Spangenberg EE, Green KN, (2017), Inflammation in Alzheimer's disease: lessons learned from microglia-depletion models. Brain Behav. Immun. 61, 1-11 
49. Liddelow SA, Guttenplan KA, Clarke LE, Bennett FC, Bohlen CJ, Schirmer L, Bennett ML, Munch, AE, Chung WS, Peterson TC, Wilton DK, Frouin A, Napier BA, Panicker N, Kumar M, Buckwalter MS, Rowitch DH, Dawson VL, Dawson TM, Stevens B, Barres BA, (2017), Neurotoxic reactive astrocytes are induced by activated microglia. Nature 541, 481-487

50. Heneka MT, Kummer MP, Stutz A, Delekate A, Schwartz S, Vieira-Saecker A, Griep A, Axt D, Remus A, Tzeng TC, Gelpi E, Halle A, Korte M, Latz E, Golenbock DT, (2013), NLRP3 is activated in Alzheimer's disease and contributes to pathology in APP/PS1 mice. Nature 493, 674678

51. Alzheimer A, Stelzmann RA, Schnitzlein HN, Murtagh FR. An English translation of Alzheimer's 1907 paper, "Uber eine eigenartige Erkankung der Hirnrinde". Clin Anat. 1995;8(6):429-31. DOI:10.1002/ca.980080612 (Alzheimer, A. 1907 Uber eine eigenartige (Erkrankung der Hirnrinde. Allgemeine Zeitschrift fur Psychiatrie und phychish-Gerichtliche Medizin, (Berlin) 64: 146-148.)

52. Verkhratsky A, Matteoli M, Parpura V, Mothet JP, Zorec R, (2016), Astrocytes as secretory cells of the central nervous system: idiosyncrasies of vesicular secretion. EMBO, J., 35, 239-57. doi: $10.15252 / \mathrm{embj} .201592705$.

53. Alibhai JD, Diack AB, Manson JC, (2018), Unravelling the glial response in the pathogenesis of Alzheimer's disease. FASEB J. 32, 5766-5777.

54. Behrendt G, Baer K, Buffo A, Curtis MA, Faull RL, Rees MI, Gotz M, Dimou L, (2013), Dynamic changes in myelin aberrations and oligodendrocyte generation in chronic amyloidosis in mice and men. Glia 61, 273-286

55. Nasrabady SE, Rizvi B, Goldman JE, Brickman AM, (2018), White matter changes in Alzheimer's disease: a focus on myelin and oligodendrocytes. Acta Neuropathol. Commun. 6, 22

56. Cai Z, Xiao M, (2016), Oligodendrocytes and Alzheimer's disease. Int. J. Neurosci. 126, 97104 
57. Ihara Y, Nukina N, Miura R, Ogawara M, (1986), Phosphorylated tau protein is integrated into paired helical filaments in Alzheimer's disease. J Biochem. 99, 1807-10.

58. Kosik KS, Orecchio LD, Bakalis S, Neve RL (1989), Developmentally regulated expression of specific tau sequences. Neuron 2, 1389-1397

59. Goedert M, Spillantini MG, Cairns NJ, Crowther RA (1992a), Tau proteins of Alzheimer paired helical filaments: abnormal phosphorylation of all six brain isoforms. Neuron 8, 159-168

60. Abramov E, Dolev I, Fogel H, Ciccotosto GD, Ruff E, Slutsky I. (2009), Amyloid-beta as a positive endogenous regulator of release probability at hippocampal synapses. Nat Neurosci. 12, 1567-76. doi: 10.1038/nn.2433. https://doi.org/10.1038/nn.2433

61. Nagahara AH, Merrill DA, Coppola G, Tsukada S, Schroeder BE, Shaked GM, Wang L, Blesch A, Kim A, Conner JM, Rockenstein E, Chao MV, Koo EH, Geschwind D, Masliah E, Chiba AA, Tuszynski MH (2009), Nat Med. Neuroprotective effects of a brain-derived neurotrophic factor in rodent and primate models of Alzheimer's disease, 15, 331-337. doi: 10.1038/nm.1912.

62. Kalisch R, Schuberr M, Jacob W, Kebler MS, Hemauer R, Wigger A, Landgraf R, Auer DP. (2006). Anxiety and Hippocampus Volume in the Rat. Neuropsychopharmacology 31, 925-932.

63. Campbell S, Marriott M, Nahmias C, MacQueen GM (2004). Lower hippocampal volume in patients suffering from depression: a meta-analysis. Am J Psychiatry 161: 598-607.

64. Zimbone S, Monaco I, Gianì F, Pandini G, Copani AG, Rizzarelli E (2018), Amyloid Beta monomers regulate cyclic adenosine monophosphate response element-binding protein functions by activating type-1 insulin-like growth factor receptors in neuronal cells. Aging Cell. 17, 1-10. doi: 10.1111/acel.12684.

65. Giuffrida ML Caraci F, Pignataro B, Cataldo S, De Bona P, Bruno V, Molinaro G, Pappalardo G, Messina A, Palmigiano A, Garozzo D, Nicoletti F, Rizzarelli E, Copani A. (2009), Beta-amyloid monomers are neuroprotective. J Neurosci. 29, 10582-10587. doi: 10.1523/JNEUROSCI.173609.2009 . 
66. Dujardin S, Colin M, Buee L, (2015), Invited review: Animal models of tauopathies and their implications for research/translation into the clinic. Neuropathol Appl Neurobiol. 41, 59-80.

67. Puzzo D, Gulisano W, Palmeri A, Arancio O, (2015), Rodent models for Alzheimer's disease drug discovery. Expert Opin Drug Discov. 10, 703-711.

68. Wisniewski T, Sigurdsson EM, (2010), Murine models of Alzheimer's disease and their use in developing immunotherapies. Biochim Biophys Acta Mol Basis Dis. 1802, 847-859.

69. Bouleau S, Tricoire H, (2015), Drosophila models of Alzheimer's disease: advances, limits, and perspectives. J Alzheimers Dis. 45, 1015-1038.

70. Newman M, Ebrahimie E, Lardelli M. (2014), Using the zebrafish model for Alzheimer's disease research. Front Genet. 5:189.

71. Huang LT, Lai MC, Wang CL, Wang CA, Yang CH, Hsieh CS, Liou CW, Yang SN, (2003), Long-term effects of early-life malnutrition and status epilepticus assessment by spatial navigation and CREB (Serine-133) phosphorylation. Developmental Brain Res 145, 213-218.

72. Ozanne SE, Hales CN, (2004), Early growth determines longevity in male rats and may be related to telomere shortening in the kidney. Nature, 427, 411-412.

73. Langley-Evans SC, Sculley DV, (2006), The association between birthweight and longevity in the rat is complex and modulated by maternal protein intake during fetal life. FEBS Lett. 580, 41503.

74. Martin-Gronert MS, Tarry-Adkins JL, Cripps RL, Chen JH, Ozanne SE, (2008), Maternal protein restriction leads to early life alterations in the expression of key molecules involved in the aging process in rat offspring. Am J Physiol Regul Integr Comp Physiol. 294, R494-R500

75. de Oliveira LM, (1985), Malnutrition and environment: interaction effects upon animal behavior. Revista Chilena de Nutrición 13, 99-108. 
76. Riul TR, Carvalho, AF, Almeida PS, De-Oliveira LM, Almeida SS, (1999), Ethological analysis of mother-pup interactions and other behavioral reactions in rats: effects of malnutrition and tactile stimulation of the pups. Braz J Med Biol Res 32, 975-983.

77. Barnes R.H, (1976) Dual role of environmental deprivation and malnutrition in retarding intellectual development. American Journal of Clinical Nutrition 29, 912-917.

78. Wainwright PE, Colombo J, (2006), Nutrition and the development of cognitive functions: interpretation of behavioral studies in animals and human infants. American Journal of Clinical Nutrition 84, 961-970.

79. Hermel EE, Severino GS, Cecconello AL, Pereira FM, Sanvitto GL, Lucion AB, (2001), Neonatal handling and the expression of immunoreactivity to tyrosine hydroxylase in the hypothalamus of adult male rats. Braz J Med Biol Res 34, 1191-1195.

80. Feoli AM, Siqueira IR, Almeida L, Tramontina AC, Vanzella C, Sbaraini S, Schweigert ID, Netto CA, Perry ML, Alves CA, (2006), Effects of protein malnutrition on oxidative status in rat brain. Nutrition 22, 160-165.

81. Sayer AA, Dunn R, Langley-Evans S, Cooper C, (2001), Prenatal exposure to a maternal low protein diet shortens life span in rats. Gerontology. 47, 9-14.

\section{FIGURE AND TABLE LEGENDS}

Figure 1. (A) Offspring bodyweight (g) at birth to 21 days of age, and (B) in 4 to 88-week-old NP $(n=20)$, as compared to LP $(n=20)$ offspring. Also, the figure shows the offspring brain and hippocampal masses $(\mathrm{g})$ in 88-week-old NP $(\mathrm{n}=5)$ as compared to age-matched LP $(\mathrm{n}=5)$ offspring (Figure $1 \mathrm{C}-\mathrm{E}$, Bottom Panels). Results are expressed as means $\pm \mathrm{SEM}$; data obtained over time were analyzed using repeated-measures ANOVA, and comparisons involving only two means within or between groups were performed using a Student's $t$-test. Welch's $t$-test was used to correct situations characterized by heteroscedasticity. When statistically significant differences were indicated between selected means, posthoc comparisons were performed using Bonferroni's contrast test. The level of significance was set at $* p<0.05$. 
Figure 2. Graphic representation of the Morris water maze test was performed with 46 and 86week-old LP $(n=20)$ compared to age-matched NP $(n=20)$ offspring to assess both working and reference memory. The working memory test consisted of 4 days of acquisition ( 4 trials/day). The time (seconds) spent to reach the platform (escape latency) was recorded in consecutive trials and expressed as each trial day's mean. Results are expressed as means \pm SEM; data obtained over time were analyzed using repeated-measures ANOVA. When statistically significant differences were indicated between selected means, posthoc comparisons were performed using Bonferroni's contrast test. The level of significance was set at $* p<0.05$.

Figure 3. Graphic representation of the elevated plus maze (EPM) test performed with 46 and 86week-old LP $(n=9)$ as compared to age-matched NP $(n=8)$ offspring (A and B Panels). Values of time spent in EPM open arm compartments are presented as percentages of the trial's total duration. The C Panel shows the proximity measure test's graphic representation performed with 86 -week-old LP $(n=8)$ compared to age-matched NP $(n=8)$ offspring. Results are expressed as means \pm SEM; comparisons involving only two means within or between groups were performed using a Student's $t$-test. The level of significance was set at $* \mathrm{p}<0.05$.

Figure 4. Effects of maternal protein restriction on 88-week-old LP ( $n=5)$ compared to agematched NP ( $\mathrm{n}=5)$ offspring on whole hippocampal cell, neurons, and non-neuronal cell quantifications. Results are depicted as scatter dot-plot and are expressed as means \pm SEM; comparisons involving only two means within or between groups were performed using a Student's $t$-test. The level of significance was set at $* \mathrm{p}<0.05$.

Figure 5. Effect of maternal protein restriction on $\beta$-amyloid, tau, BDNF, HSP70, HSP90, IGF1R, pPI3K, and ERK2 proteins, measured using immunoblotting analysis, in the isolated whole hippocampus of 88-week-old LP $(n=4)$ as compared to age-matched NP $(n=4)$ rats. Results are expressed as means \pm SEM; only one offspring of each litter was used for immunoblotting experiments. A comparison involving only two samples of independent observations was performed using a Student's $t$-test. The level of significance was set at $* \mathrm{p}<0.05$.

Figure 6. Survival curve evaluated using Mantel-Cox and Gehan-Breslow-Wilcoxon tests in NP (n $=10)$ compared to LP $(n=10)$ offspring. Results are expressed as means \pm SEM; the significance level was set at $* \mathrm{p}<0.05$. 
Table 1. Composition of standard rodent laboratory diet (standard normal-protein (NP) diet, 17\% and low-protein (LP) diet, 6\% (AIN 93G)

\section{SUPPLEMENTAL INFORMATION}

\section{METHODS}

\section{MWM proximity measure}

The proximity measure optimized computer tracking to identify a rat's position relative to the target location; it is considered highly sensitive to age-related learning/memory impairment in aged rats [24]. This study uses new proximity measures to the behavioral analysis of learning in the water maze task. We did this to test the memory/learning ability based on the proximity measure for use in characterizing individual differences in the effects of aging on spatial learning.

The need for such an index was based on the previously identified limitations of the customary analysis and on certain special features of the effects of aging on spatial learning ability.

The present study used the proximity of the animal's position to provide several training trials and probe trial performance analyses. The proximity measure was obtained by sampling the animal's position in the maze (10 times per second) to record its distance from the escape platform in 1-s averages.

By this method, scores obtained with the proximity measure are designed to reflect search error; they represent deviations from an optimal search, from a direct path to the goal (hidden platform) in the water maze.

The assessment of proximity to the target provides a more efficient analysis method than the multiple measures traditionally used to characterize probe trial performance: platform crossings and path length or time in the quadrant.

An analysis of young rat performance that used this measure showed rapid acquisition of improved search accuracy during the interpolated probe trials. Comparison of young and aged groups demonstrated that age was most pronounced relatively early in training because aged rats acquired a spatial bias more slowly. Thus, in this study, the probe trial analysis using proximity to the target was sensitive to an age-related impairment in spatial learning.

It appears that some rats become less proficient in learning the information that is required for efficient navigation to a specific location. So, the method used here offered a sensitive, efficient, and valid approach to assessing this age-related cognitive deficit. 


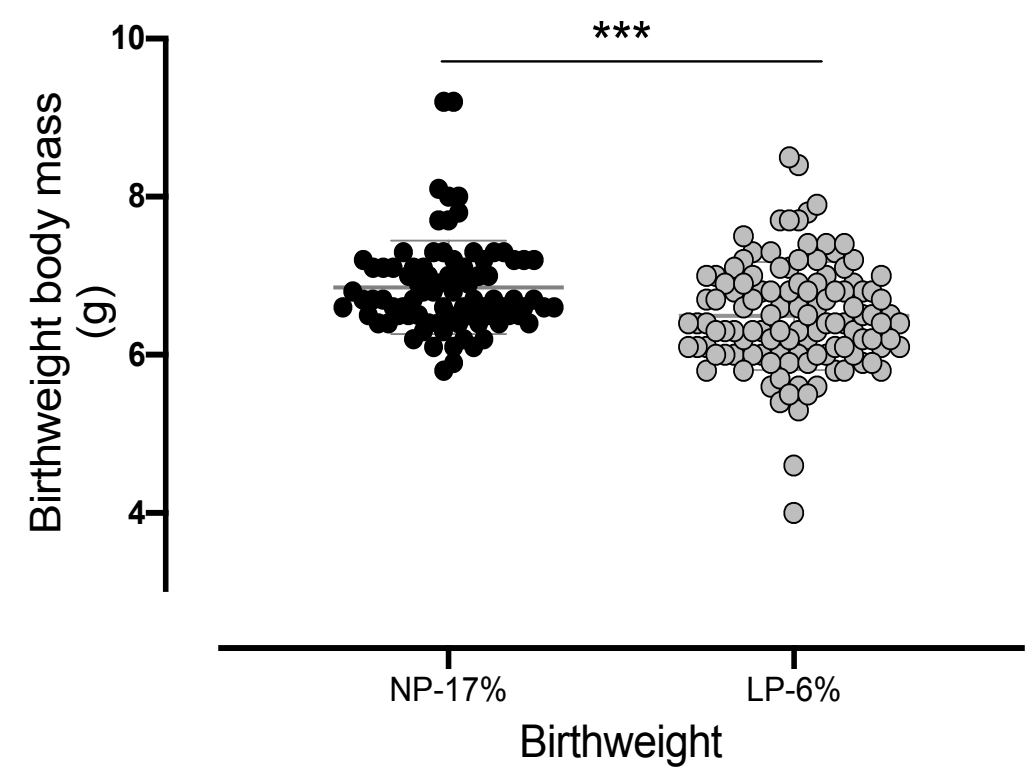

Figure S1. Offspring bodyweight (g) at birth NP progeny as compared to LP offspring. Results are depicted as scatter dot-plot and are expressed as means \pm SEM; the comparisons involving only two means within or between groups were performed using a Student's $t$-test. Welch's $t$-test was used to correct situations characterized by heteroscedasticity. When statistically significant differences were indicated between selected means, posthoc comparisons were performed using Bonferroni's contrast test. The level of significance was set at $* p<0.05$.
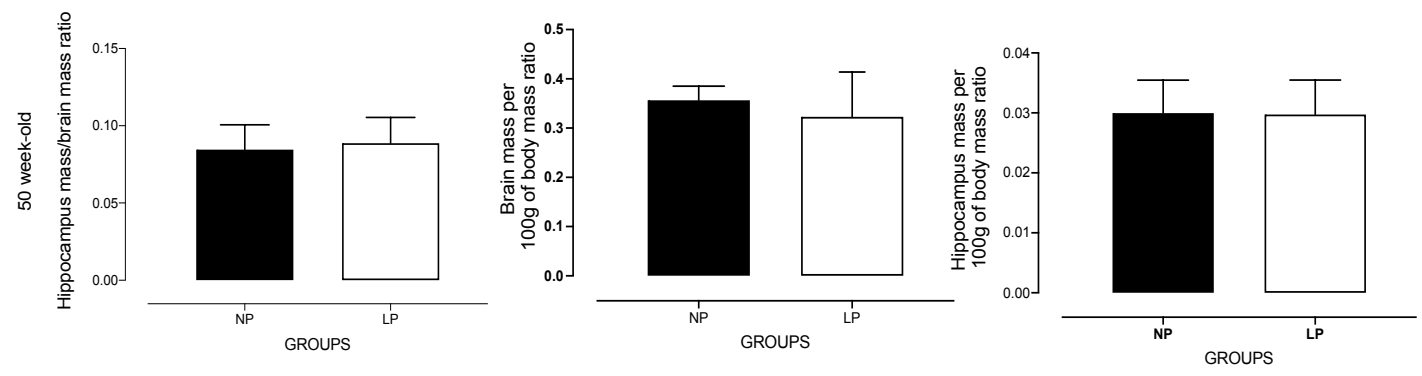

Figure S2. Offspring brain and hippocampal masses (g) in 50-week-old NP ( $\mathrm{n}=5)$ compared to agematched LP $(n=5)$ offspring. Results are expressed as means \pm SEM; comparisons involving only two means within or between groups were performed using a Student's $t$-test. The level of significance was set at $* \mathrm{p}<0.05$. 
bioRxiv preprint doi: https://doi.org/10.1101/2021.04.07.438796; this version posted April 7, 2021. The copyright holder for this preprint (which was not certified by peer review) is the author/funder, who has granted bioRxiv a license to display the preprint in perpetuity. It is made available under aCC-BY 4.0 International license.

Table 1.

\begin{tabular}{|c|c|c|}
\hline Diet composition & AIN-93G diet 6\% (in \%) & AIN-93G diet $17 \%$ (in \%) \\
\hline Cornstarch & $48.0 \%$ & $39.67 \%$ \\
\hline Dextrinizade Starch (90-94\%) & $15.9 \%$ & $13.05 \%$ \\
\hline Sucrose & $12.1 \%$ & $10.0 \%$ \\
\hline Carbohydrate & $76.0 \%$ & $62.72 \%$ \\
\hline Casein $(84 \%)$ & $7.15 \%$ & $20.23 \%$ \\
\hline L-cysteine & $0.1 \%$ & $0.3 \%$ \\
\hline Cholin bitartrate & $0.25 \%$ & $0.25 \%$ \\
\hline Protein & $7.5 \%$ & $20.78 \%$ \\
\hline Soybean oil & $7.0 \%$ & $7.0 \%$ \\
\hline Total fats & $7.0 \%$ & $7.0 \%$ \\
\hline Cellulose microfine (fiber) & $5.0 \%$ & $5.0 \%$ \\
\hline Fiber & $5.0 \%$ & $5.0 \%$ \\
\hline Mineral mix & $3.5 \%$ & $3.5 \%$ \\
\hline \multirow[t]{2}{*}{ Vitamin mix } & $1.0 \%$ & $1.0 \%$ \\
\hline & $100 \%$ & $100 \%$ \\
\hline BHIT (Butylhydroxitoluol) & $0.0014 \%$ & $0.0014 \%$ \\
\hline Energy content & $3.88 \mathrm{kcal} . \mathrm{g}^{-1}$ of chow & $3.80 \mathrm{kcal} \mathrm{g}^{-1}$ of chow \\
\hline
\end{tabular}




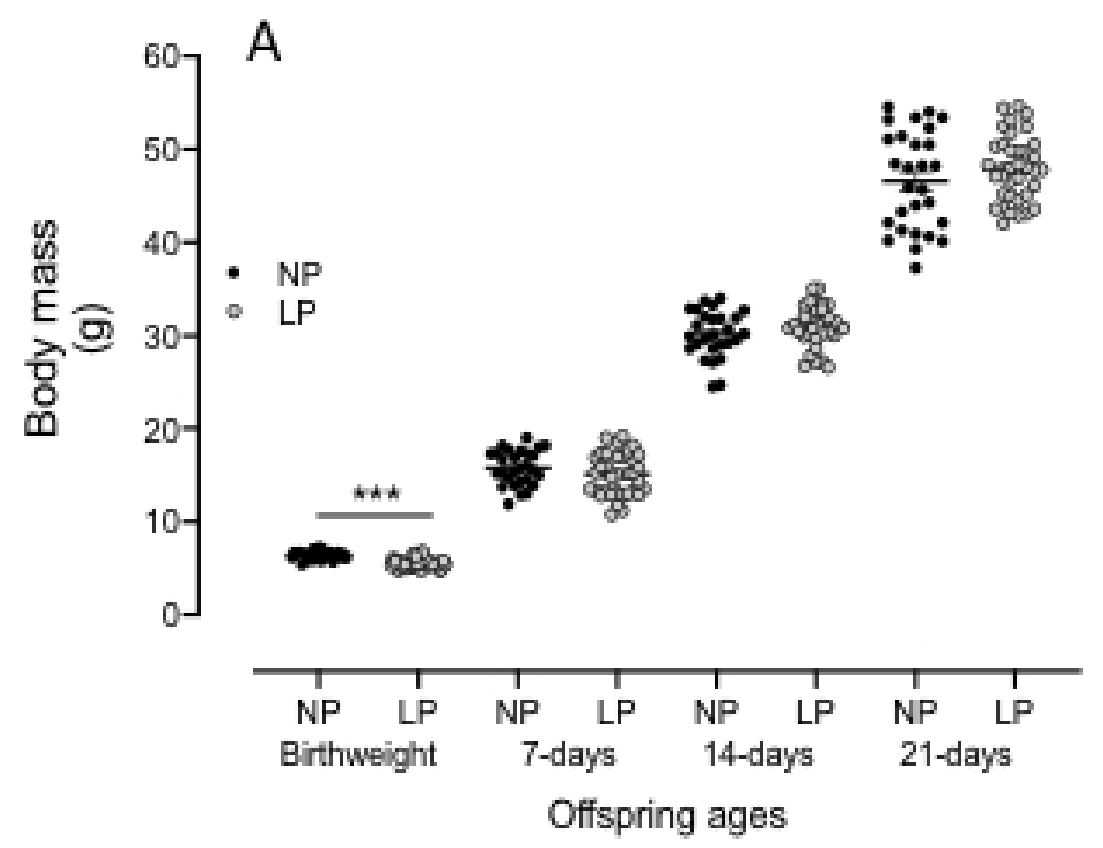

B
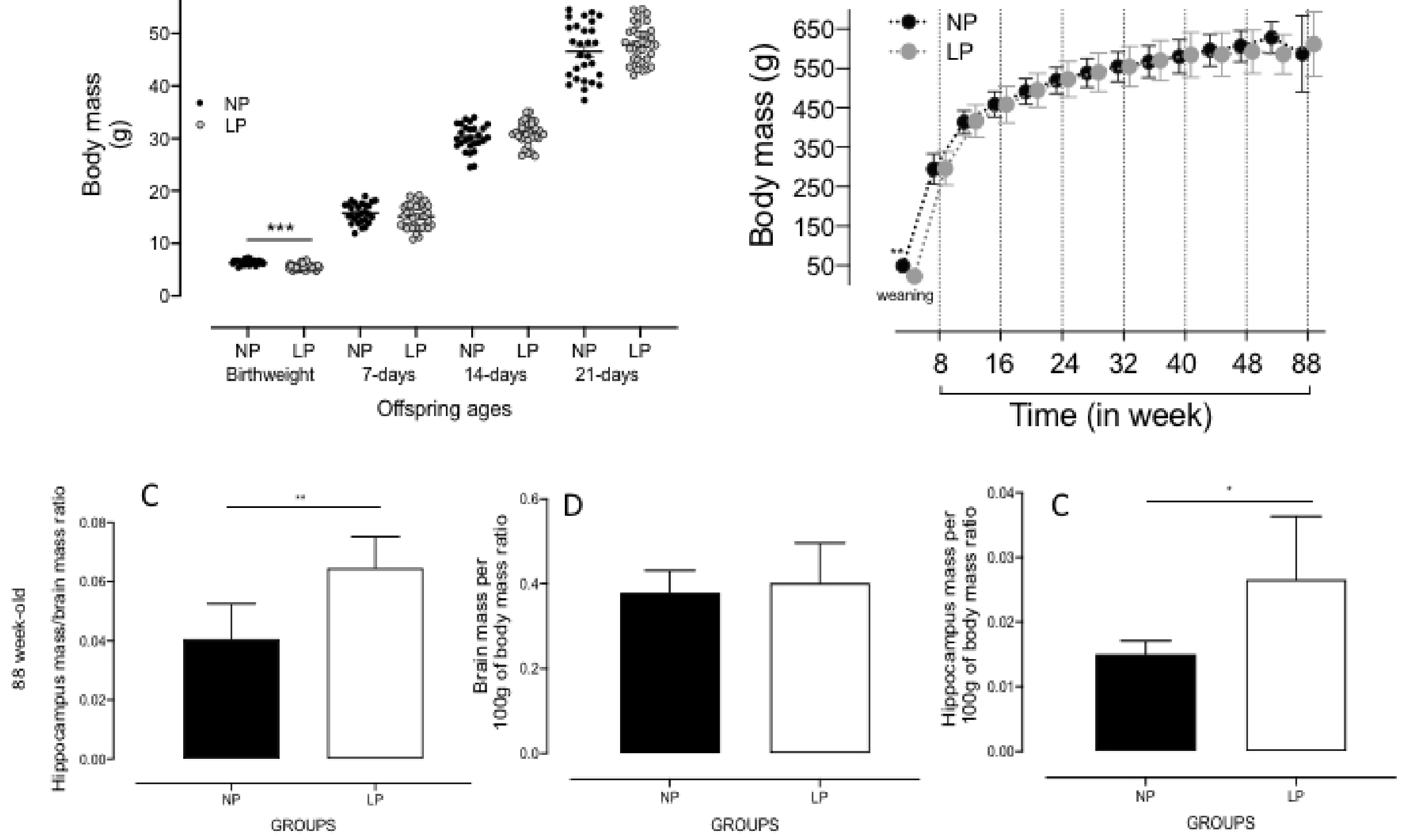

Figure 1

Figure 1 
Working Memory
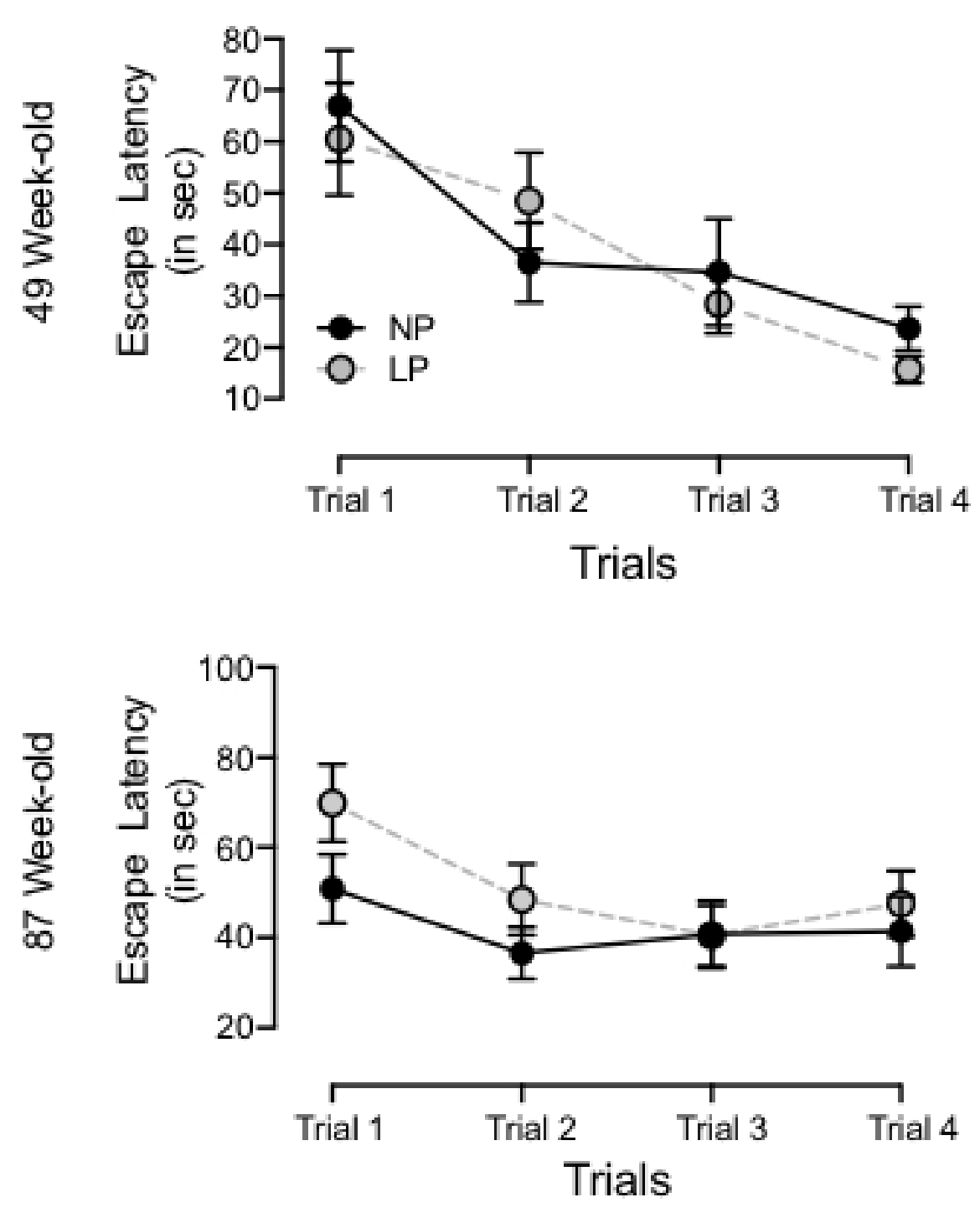

Reference Memory
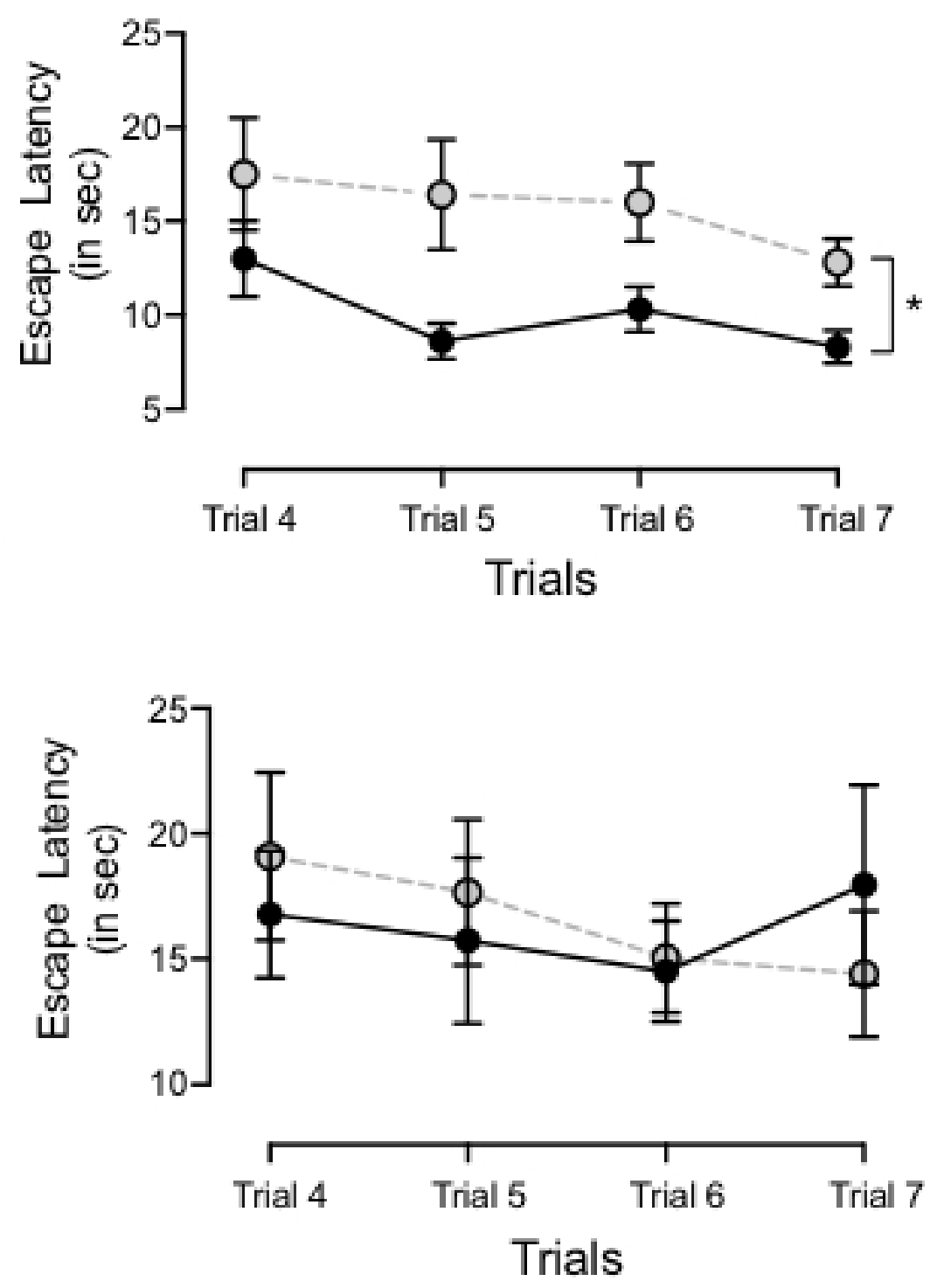

Figure 2 


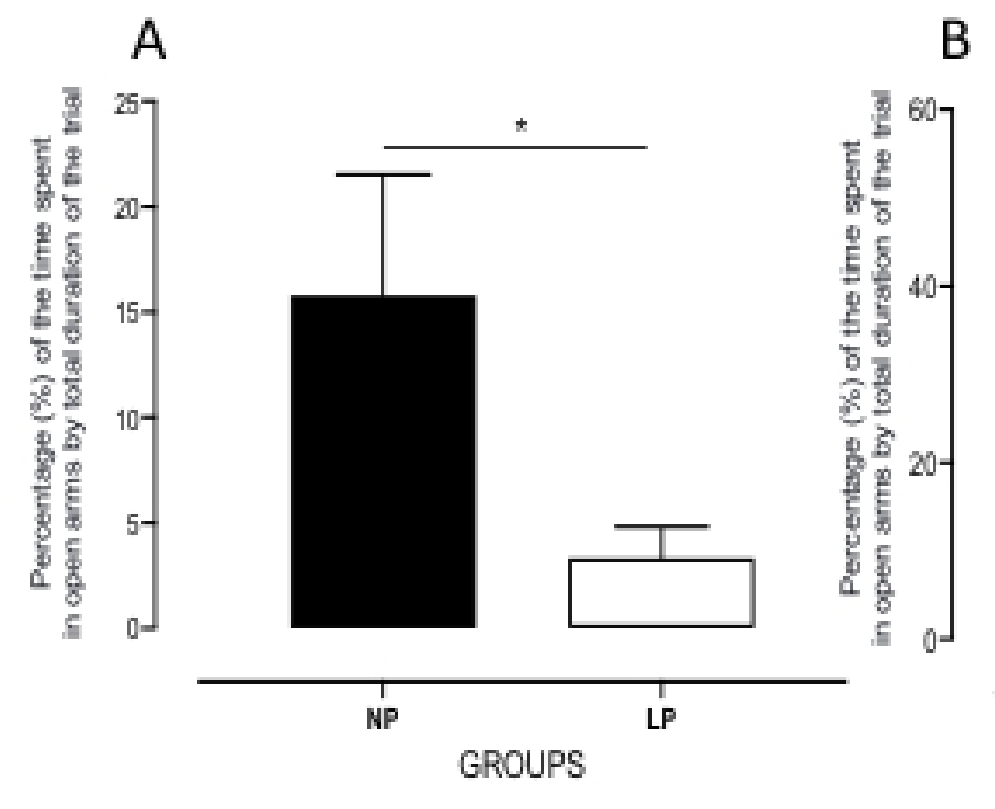

48 week-old

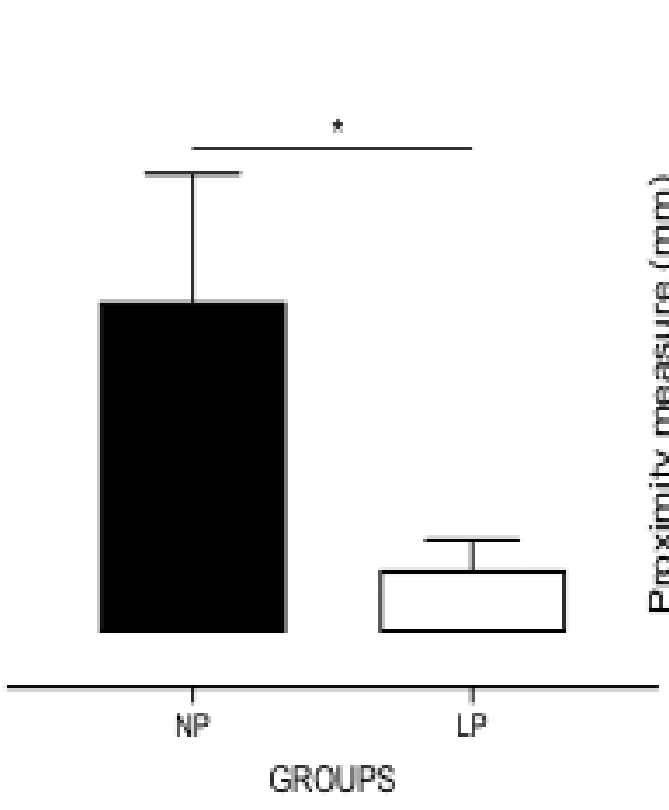

86 week-old

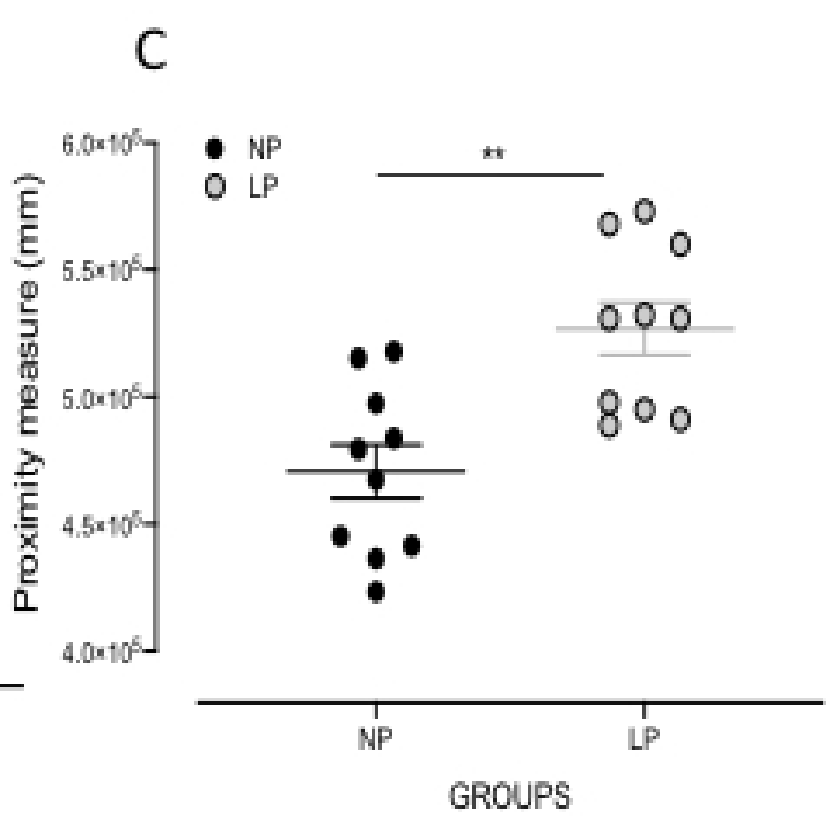

Figure 3

Figure 3 

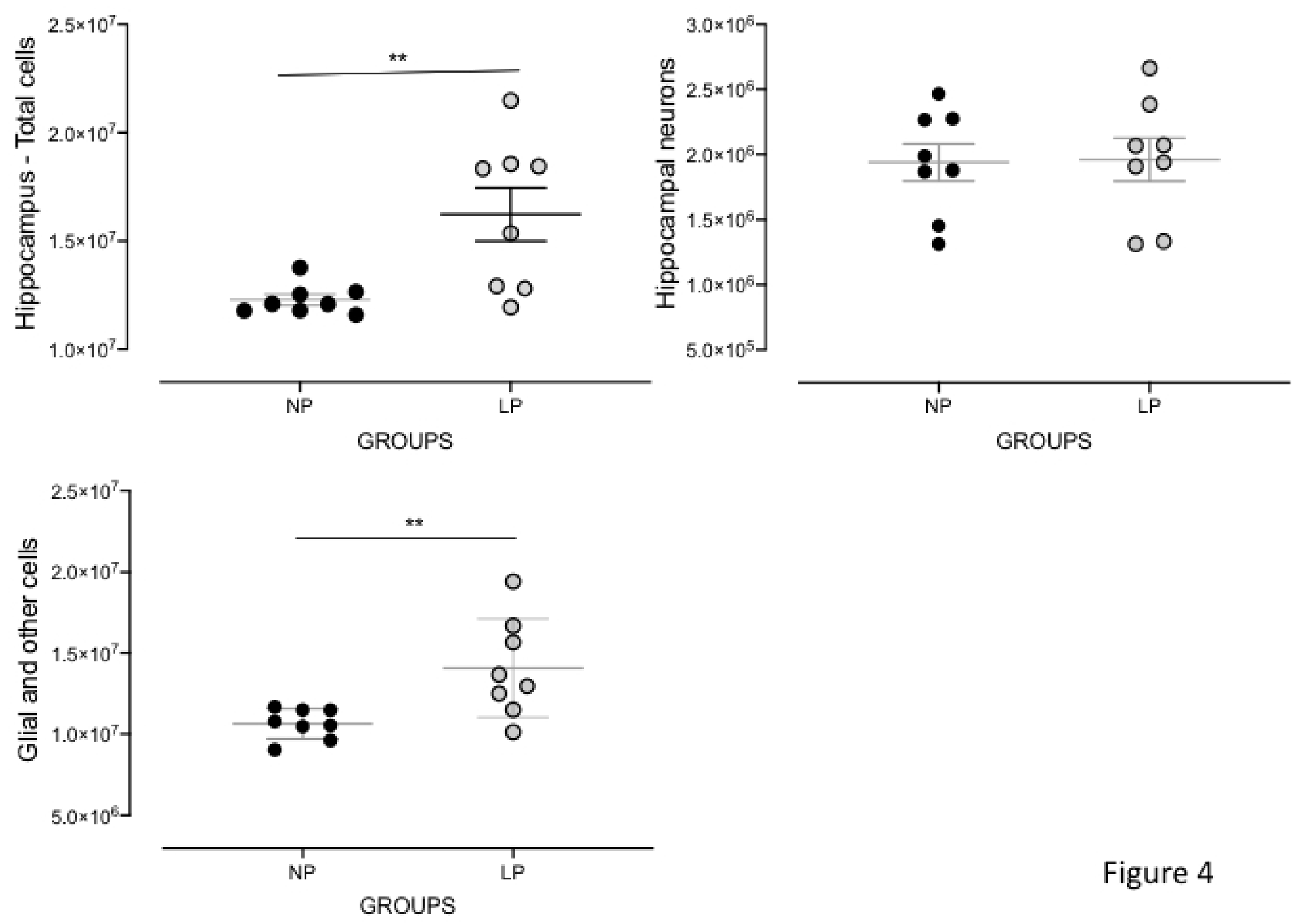

Figure 4

Figure 4 

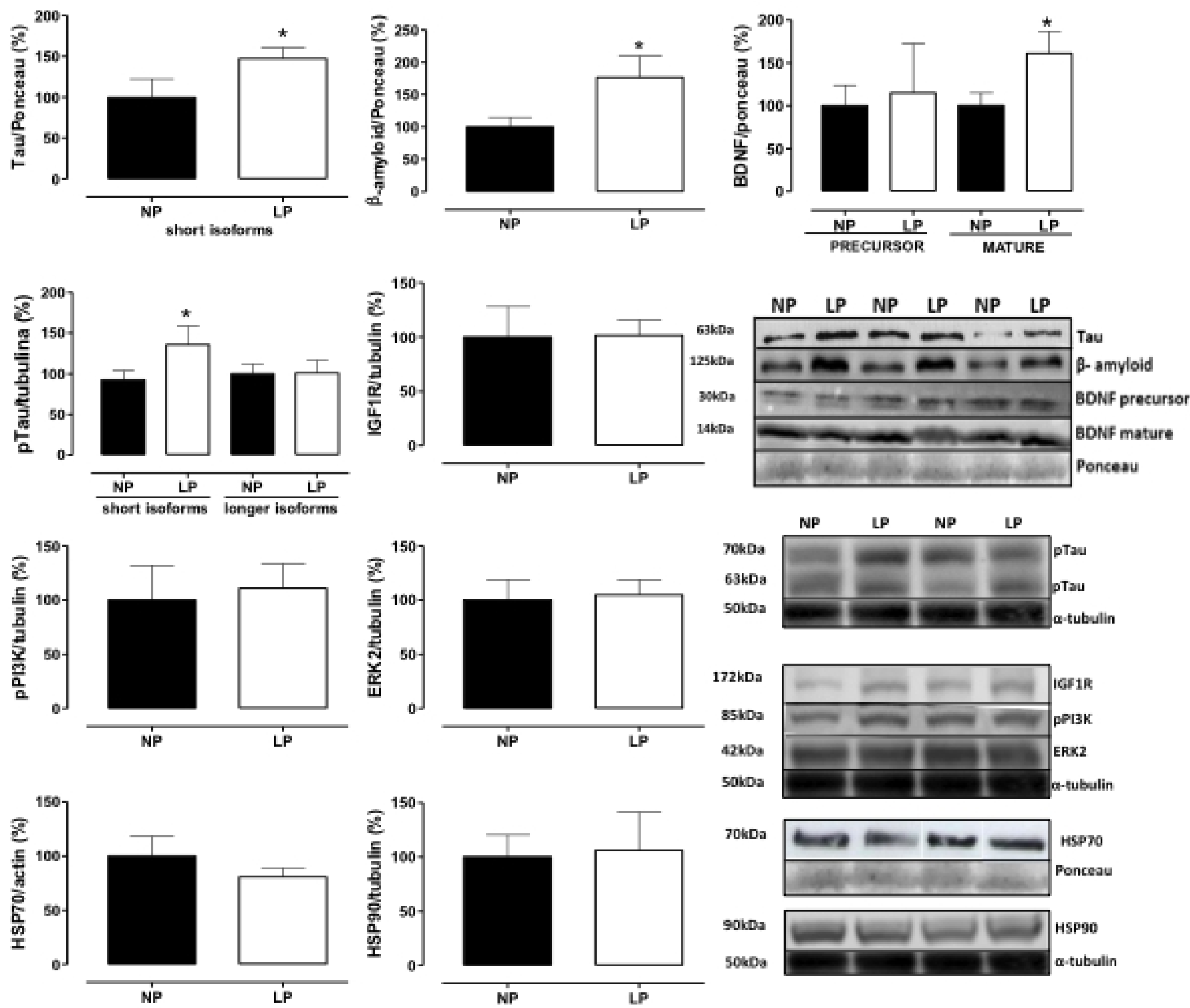

70kDa

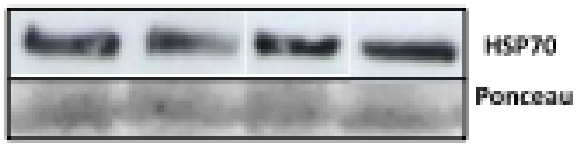

9okda

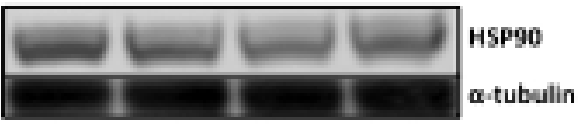

Figure 5

Figure 5 


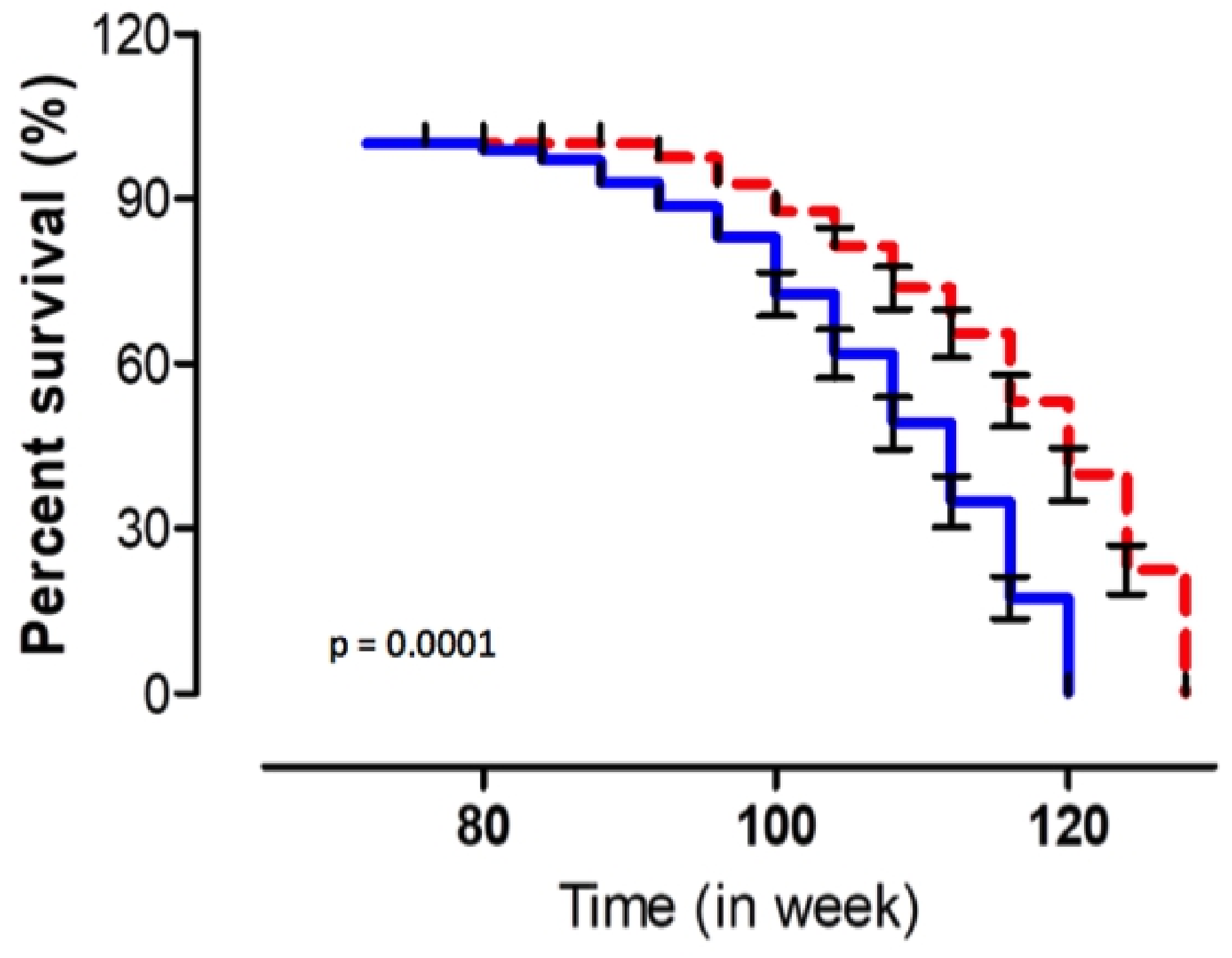

